\title{
Network Reconfiguration for Loss Reduction and Voltage Profile Improvement of 110-Bus Radial Distribution System Using Exhaustive Search Techniques
}

\author{
Su Mon Myint, Soe Win Naing \\ Department of Electrical Power Engineering, Mandalay Technological University, Patheingyi, Myanmar
}

\begin{abstract}
Article Info
Article history:

Received Mar 22, 2015

Revised May 9, 2015

Accepted May 24, 2015

\section{Keyword:}

Exhaustive techniques

Load flow analysis

Loss reduction

Network reconfiguration

Radial distribution system

ABSTRACT

Nowadays, the electricity demand is increasing day by day and hence it is very important not only to extract electrical energy from all possible new power resources but also to reduce power losses to an acceptable minimum level in the existing distribution networks where a large amount of power dissipation occurred. In Myanmar, a lot of power is remarkably dissipated in distribution system. Among methods in reducing power losses, network reconfiguration method is employed for loss minimization and exhaustive technique is also applied to achieve the minimal loss switching scheme. Network reconfiguration in distribution systems is performed by opening sectionalizing switches and closing tie switches of the network for loss reduction and voltage profile improvement. The distribution network for existing and reconfiguration conditions are modelled and simulated by Electrical Transient Analyzer Program (ETAP) 7.5 version software. The inputs are given based on the real time data collected from $33 / 11 \mathrm{kV}$ substations under Yangon Electricity Supply Board (YESB). The proposed method is tested on 110-Bus, overhead AC radial distribution network of Dagon Seikkan Township since it is long-length, overloaded lines and high level of power dissipation is occurred in this system. According to simulation results of load flow analysis, voltage profile enhancement and power loss reduction for proposed system are revealed in this paper.
\end{abstract}

Copyright (C) 2015 Institute of Advanced Engineering and Science. All rights reserved.

\section{Corresponding Author:}

Su Mon Myint,

Department of Electrical Power Engineering, Mandalay Technological University

Patheingyi, Mandalay, Myanmar

Email: sumonmyint10@gmail.com

\section{INTRODUCTION}

The increase in power demand and high load density in the urban areas makes the operation of power systems complicated. The power distribution topology is required to change for the better planning of primary distribution system and by increasing the substation capacity and the number of feeders according to obtain the minimal loss configuration. A significant portion of the power that a utility generates is lost in the distribution process. These losses occur in numerous small components in the distribution system, such as transformers and distribution lines [1]. One of the major sources of losses in the distribution system is the power lines which connect the substation to the loads. Virtually all real power is lost in the distribution system since these losses are a function of the square of the current flow through the line. Minimization of active power losses is one of the essential aims for any electrical distribution to improve system properties and meet the customer demand. Network reconfiguration, capacitor placement and distributed generation are among different ways of decreasing losses. As a consequence, the system voltage is also improved. Thus, these two facts are interconnected [2]. As distribution system of case study is radial distribution system, distribution feeder configuration is the best method. Distribution feeder reconfiguration is performed for load 
balancing and loss reduction during the load transfer from heavy loaded feeder to light loaded feeder. After finding the statues of different switches, the feeder can be configured from a distant place. There are two types of switches: normally open switches as tie-switch and normally close switches as sectionalizing switch. By closing tie switches in radial distribution system, this network transforms into fully meshed distribution system. In this condition, system power losses are decreased. This is the least power losses the system can have. And the function of sectionalizing switches is to open line between buses in a loop to restore radial distribution system finally. It is noted that if there are five loops in the system, this system should have five sectionalizing switches to be radial distribution network [3].

\section{ETAP MODEL IN POWER FLOW ANALYSIS}

Power flow analysis is important for planning future expansion of power systems as well as in determining the best operation of existing systems. The principal information obtained from the power flow analysis is the magnitude and phase angle of the voltage at each bus, and the real and reactive power flowing in each line [4]. In the electrical power system losses, technical losses are more important than non-technical losses for designing the electrical power distribution system. These losses can still be grouped according to the segment of the electric system where it happens, can be subdivided into losses in the transmission system, substation power transformers, primary distribution system, secondary distribution system connection extensions. One of the main sources of losses is the copper losses in the distribution system in power overhead lines and cables since these losses are a function of current flows through the lines. These losses can also be reduced by network reconfiguration [5]. Dagon Seikkan network which is chosen as a case study area has many industrial loads, commercial loads, other departments and residential loads [6]. Real power, reactive power and volt drop of each bus are calculated by using Newton Raphson method for load flow solutions. It is more suitable for large scale of power system because it is more practical and efficient. The total power loss of feeders may then be determined by summing up the losses of all line sections of the feeder which is:

$$
\begin{aligned}
& \mathrm{P}_{\text {Peak Loss }}=\sum_{\mathrm{mn}=1}^{\mathrm{k}}\left|\mathrm{I}_{\mathrm{mn}}\right|^{2} \times \mathrm{R}_{\mathrm{mn}} \\
& \mathrm{Q}_{\text {Peak }} \text { Loss }=\sum_{\mathrm{mn}=1}^{\mathrm{k}}\left|\mathrm{I}_{\mathrm{mn}}\right|^{2} \times \mathrm{X}_{\mathrm{mn}} \\
& \mathrm{I}_{\mathrm{mn}}=\frac{\mathrm{P}_{\mathrm{mn}}-\mathrm{Q}_{\mathrm{mn}}}{\mathrm{V}_{\mathrm{m}}}
\end{aligned}
$$

Percentage change in the power loss reduction can be defined by:

$$
\% \text { Power Loss }=\frac{\mathrm{P}_{\mathrm{LB}}-\mathrm{P}_{\mathrm{LA}}}{\mathrm{P}_{\mathrm{LB}}} \times 100
$$

where;

$$
\begin{aligned}
& \mathrm{I}_{\mathrm{mn}}=\text { Current through in the branch }(\mathrm{m}, \mathrm{n}) \\
& \mathrm{V}_{\mathrm{m}}=\text { Voltage at node } \mathrm{m} \\
& \mathrm{P}_{\mathrm{mn}}=\text { Real power through in the branch }(\mathrm{m}, \mathrm{n}) \\
& \mathrm{R}_{\mathrm{mn}}=\text { Resistance in the branch }(\mathrm{m}, \mathrm{n}) \\
& \mathrm{X}_{\mathrm{mn}}=\text { Reactance in the branch }(\mathrm{m}, \mathrm{n}) \\
& \mathrm{P}_{\mathrm{LA}}=\text { Power loss after reconfiguration } \\
& \mathrm{Q}_{\mathrm{mn}}=\text { Reactive power through in the branch }(\mathrm{m}, \mathrm{n}) \\
& \mathrm{P}_{\mathrm{LB}}=\text { Power loss before reconfiguration [5] }
\end{aligned}
$$

The power flow equations are the following:

Load Flow: $\mathrm{F}(\mathrm{x}, \mathrm{u})=0$

$$
\mathrm{P}_{\mathrm{i}, \mathrm{n}}=\sum_{\mathrm{j}=1}^{\mathrm{N}_{\mathrm{B}}}\left|\mathrm{Y}_{\mathrm{ij}} \mathrm{V}_{\mathrm{i}, \mathrm{n}} \mathrm{V}_{\mathrm{j}, \mathrm{n}}\right| \cos \left(\vartheta_{\mathrm{ij}}+\delta_{\mathrm{j}, \mathrm{n}}-\delta_{\mathrm{i}, \mathrm{n}}\right)
$$




$$
\mathrm{Q}_{\mathrm{i}, \mathrm{n}}=-\sum_{\mathrm{j}=1}^{\mathrm{N}_{\mathrm{B}}}\left|\mathrm{Y}_{\mathrm{ij}} \mathrm{V}_{\mathrm{i}, \mathrm{n}} \mathrm{V}_{\mathrm{j}, \mathrm{n}}\right| \sin \left(\vartheta_{\mathrm{ij}}+\delta_{\mathrm{j}, \mathrm{n}}-\delta_{\mathrm{i}, \mathrm{n}}\right)
$$

Bus Voltage Constraint: $V_{\min } \leq \mathrm{V} \leq \mathrm{V}_{\max }$ for all PQ buses

Radial Constraint:

The distribution system topology should be in series connection to minimize the complexity in calculating power flow.

ETAP software is one of the efficient software to analyze the very complex power systems including short circuit calculation, battery sizing, transformer sizing, load flow, volt drop, system losses, transient stability, ground grid design, optimal capacitor placement and so on. Among these applications, ETAP is applied for load flow calculations of before and after reconfiguration states because it can quickly and easily build 3-phase AC network one line diagram with unlimited buses and elements. Single line diagram of case study, ratings of power transformers and distribution transformers and actual ratings of line parameters are needed to simulate for load flow solution of existing system. This allow the proper layout for the distribution feeders in township to be made in the form of single line diagram which enables a better understanding the loss calculation of the location in a more precise way [7]. Current flowing in every branch, line losses, bus voltage, power factor and percentage in volt drop on the feeder of the existing system and proposed system can be calculated by this software. In power flow analysis of case study, the ratings of all equipments are chosen by IEC standard in ETAP. Load flow calculation is performed for both conditions i.e., before and after network reconfiguration of 110-Bus distribution network. The load flow solutions for three methods in exhaustive search techniques are needed to manage optimal switching configuration of test system.

\section{OVERVIEW OF 110-BUS RADIAL DISTRIBUTION NETWORK}

The system under study is one of the $11 \mathrm{kV}$ distribution networks under Yangon Electricity Supply Board (YESB). The distribution networks are located in Dagon Seikkan Township in Yangon. The single line diagram of Dagon Seikkan Township is shown in Figure 1. Incoming line is $33 \mathrm{kV}$ and outgoing line is $11 \mathrm{kV}$. The distribution voltage of the system under study is $11 \mathrm{kV}$. Step down power transformer is used to distribute power and its rating is 10MVA and power factor is 0.85 . Although installed capacities for Station, Kanaung Minthar and Mingyimahar Kaung are $50 \mathrm{kVA}, 16365 \mathrm{kVA}$ and $24450 \mathrm{kVA}$, connected loads for each feeder are $0.54 \mathrm{kVA}, 1933 \mathrm{kVA}$ and $2594 \mathrm{kVA}$ because some distribution transformers are not full load condition. So, the total load for three feeders is $4.52754 \mathrm{MVA}$. Load of this system receives a voltage of $400 \mathrm{~V}$ and type of load is lump load. The value of power factor for distribution transformer is 0.83 . Conductor size for $33 \mathrm{kV}$ is $120 \mathrm{~mm}^{2}$ and $11 \mathrm{kV}$ is $95 \mathrm{~mm}^{2}$. ACSR conductor is used for incoming and outgoing feeders. The distribution system is radial distribution system [6].

\section{NETWORK RECONFIGURATION IN ELECTRICAL DISTRIBUTION SYSTEM}

System reconfiguration means restructuring the power lines which connect various buses in a power system. Restructuring of specific lines leads to alternate system configurations. System reconfiguration can be accomplished by placing line interconnection switches into network. Opening and closing a switch connects or disconnect a line to the existing network. Network reconfiguration in distribution systems is performed by opening sectionalizing (normally closed) and closing tie (normally open) switches of the network. These switching are performed in such a way that the radiality of the network is maintained and all the loads are energized. A normally open tie switch is closed to transfer a load from one feeder to another while an appropriate sectionalizing switch is opened to restore the radial structure.

During applying reconfiguration technique, the tie switch has to be closed and on the other hand, the sectionalizing switch has to be opened in the loop created, which restores radial configuration. The switch pairs are chosen through exhaustive formulas for the change in losses. Branch exchange process is repeatedly applied till no more loss reductions are available. A radial distribution network can be represented by several loops. This is because, when it is connected, one tie-line can only make one loop, the number of loops is equal to the number of tie-lines [9]. The benefits of feeder reconfiguration include: (i) restoring power to any outage partitions of a feeder, (ii) relieving overloads on feeders by shifting the load in real time to adjacent feeders, and (iii) reducing resistive line losses. Optimal reconfiguration involves the selection of the best set of branches to be opened, one each from each loop, for reducing resistive line losses, and reliving overloads on feeders by shifting the load to adjacent feeders [10]. 


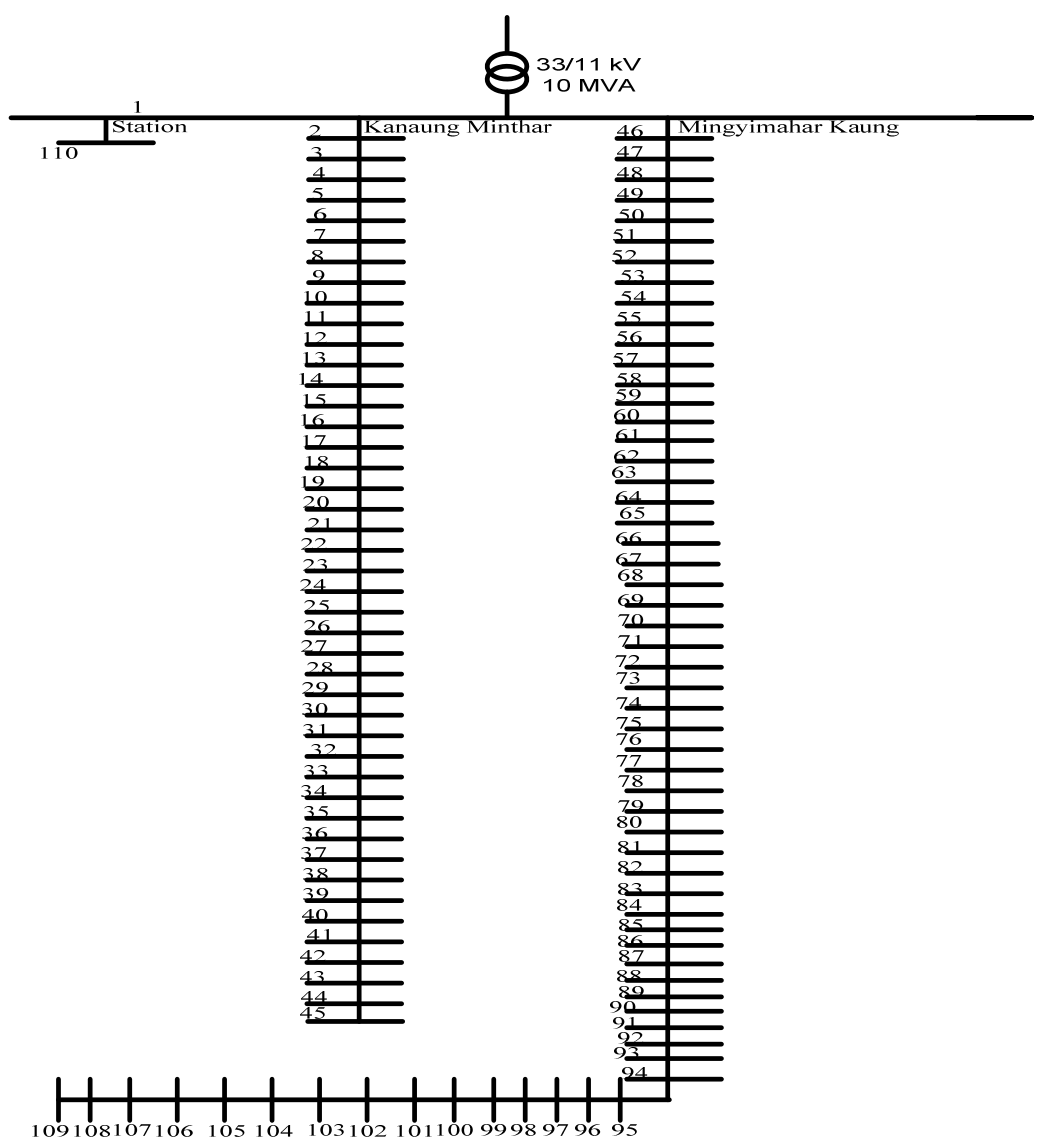

Figure 1. Single line diagram of 110-Bus system [6]

\section{EXHAUSTIVE TECHNIQUES IN NETWORK RECONFIGURATION}

Reconfiguration is an indispensable method for loss reduction in power distribution systems. This paper focuses on reconfiguration of a radial distribution networks to optimize the power distribution process in the feeders and for voltage profile improvement and presents three different methods for reconfiguration. Feeder reconfiguration is done to minimize losses for the existing and new topology of the feeder system and for the purpose of maintenance in the distribution system. The schematic diagram of 110-Bus existing radial distribution system is illustrated in Figure 2.

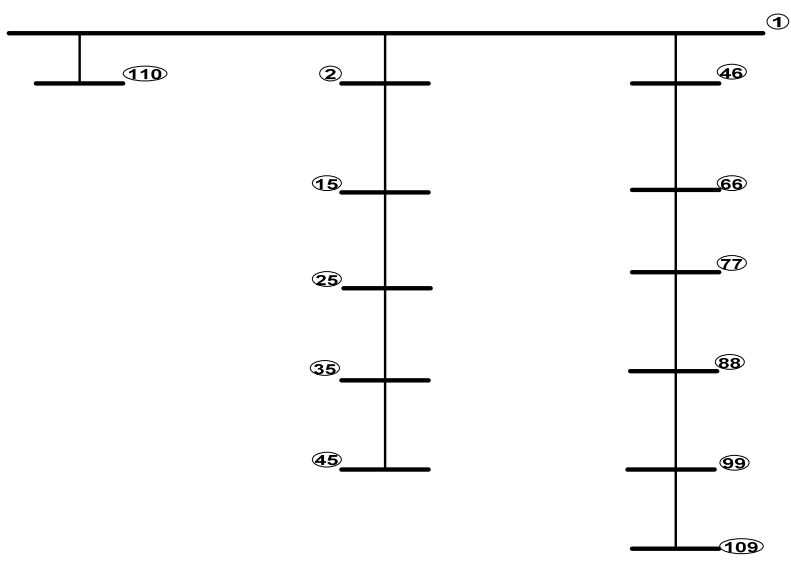

Figure 2. 110-Bus Existing radial system 
Figure 3 shows the connection of 110-Bus system with tie lines. An exhaustive technique for the reconfiguration of distribution networks is used to reduce their line losses under normal operating conditions. There are three types of methods in exhaustive search technique for loss reduction. They are minimum branch current, minimum voltage difference and voltage difference based closing/opening switch. The proposed approach is suitable for both planning and operation studies as it is computationally robust and efficient [10]. In this paper, three different methods are proposed with initial configuration and meshed topologies. The initial meshed topology gives the minimum loss configuration for the system and as the network is reconfigured, the radial configuration with minimum losses will occur. The reduction in losses can easily be computed from the results of two load flow studies of the system configuration before and after the feeder reconfiguration. The load flow solutions of both cases are modeled and simulated by using ETAP software. Newton Raphson load flow has been used in the entire reconfiguration process because the convergence clip is appreciably swift. When the switching is performed, the network needs to be maintained in radial form.

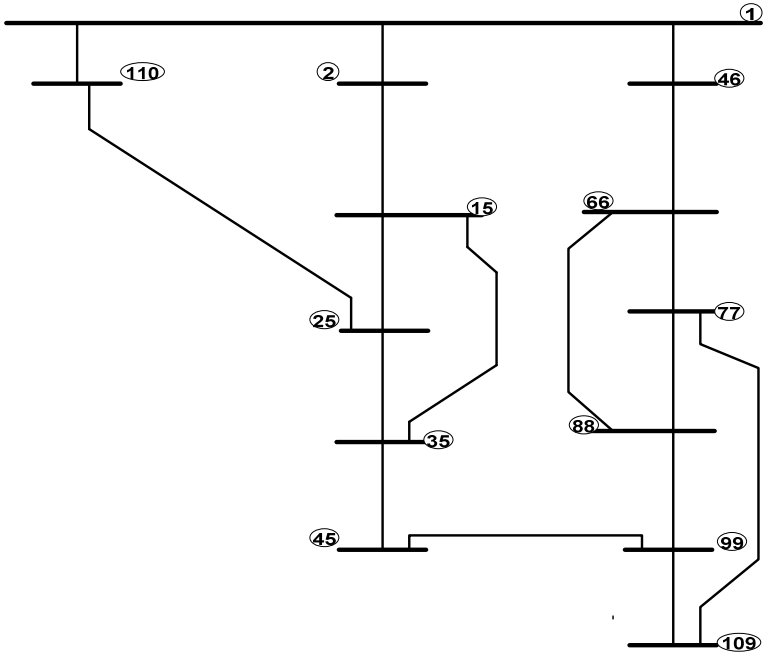

Figure 3. 110-Bus Fully meshed system

Three different methods for reconfiguration of 110-Bus system are illustrated in Figure 4, Figure 5 and Figure 6. The voltage profiles and loss reduction in respective cases are compared subsequently. Three different methods are as follow:

Method 1: Minimum Branch Current Based Reduction

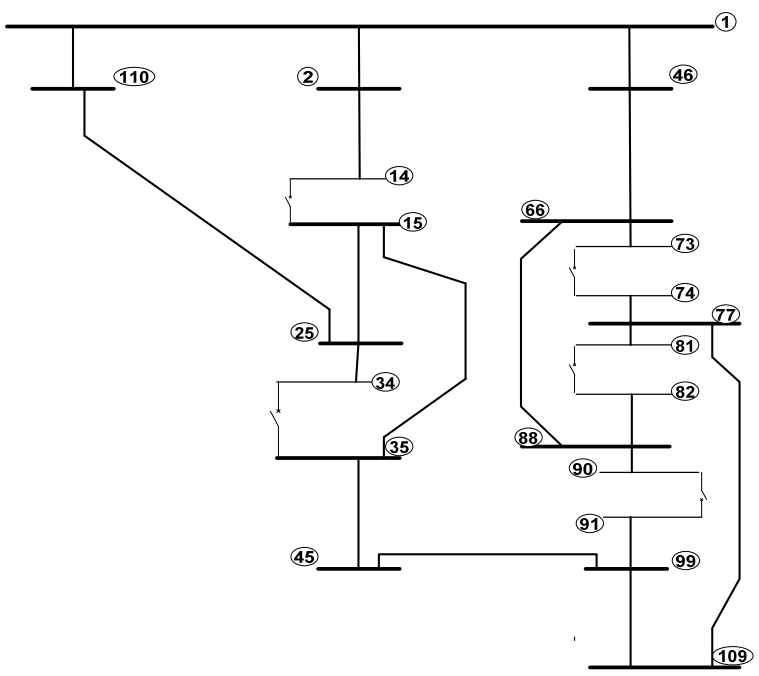

Figure 4. 110-Bus Final radial configuration using method 1 
a) Active power loss for 110-Bus radial distribution system must be calculated. It comes out to be (243.6) $\mathrm{kW}$.

b) Active power loss for 110-Bus meshed distribution system must be calculated. It comes out to be (157.7) $\mathrm{kW}$. This is the least power loss the system can have. The aim is to reach the most feasible radial state in terms of power loss by opening sectionalizing switches in each loop such that radiality is maintained and none of the loads is isolated.

c) After power flow in base case, sort minimum branch current to open that branch at minimum current. By doing this, increase in power loss will also be very small.

d) Repeat load flow and open the switch with minimum branch current, such that it lies in different loop, no load is isolated and radial structure is maintained.

e) Since five loops have been created due to tie switches, hence five sectionalizing switches will be opened corresponding to each loop. Repeat step (d) till the network is radial and note down the final configuration power loss.

f) Final configuration power loss comes out to be (175.3) $\mathrm{kW}$. Calculate percentage power loss reduction using equation (4).

Final radial configuration of 110-Bus using method 1 is shown in Figure 4.

Method 2: Minimum Voltage Difference Based Reduction

a) Active power loss for 110-Bus radial distribution system must be calculated. It comes out to be (243.6) $\mathrm{kW}$.

b) Active power loss for 110-Bus meshed distribution system must be calculated. It comes out to be (157.7) $\mathrm{kW}$. This is the least power loss the system can have. The aim is to reach the most feasible radial state in terms of power loss by opening sectionalizing switches in each loop such that radiality is maintained and none of the loads is isolated.

c) After power flow in base case, sort minimum voltage difference branch to open that branch at minimum voltage difference.

d) Repeat load flow and open the switch with minimum voltage difference, such that it lies in different loop, no load is isolated and radial structure is maintained.

e) Since five loops have been created due to tie switches, hence five sectionalizing switches will be opened corresponding to each loop. Repeat step (d) till the network is radial and note down the final configuration power loss.

f) Final configuration power loss comes out to be (175.6) $\mathrm{kW}$. Calculate percentage power loss reduction using equation (4).

Final radial configuration of 110-Bus using method 2 is illustrated in Figure 5.

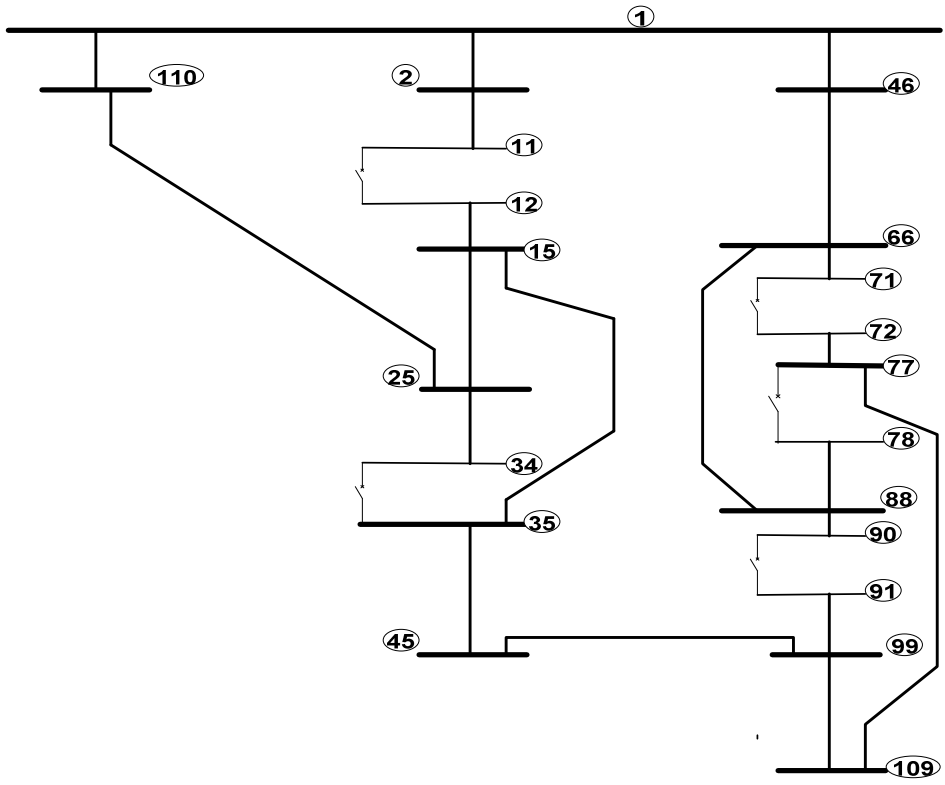

Figure 5. 110-Bus Final radial configuration using method 2 
Method 3: Voltage Difference Based Closing /Opening Switch Method

a) Active power loss for 110-Bus radial distribution system must be calculated. It comes out to be (243.6) $\mathrm{kW}$.

b) Calculate voltage difference across all tie switches after base case load flow and choose them in descending order. This will be the sequence of closing switches.

c) Close the first tie switches with maximum voltage difference across it and run the load flow on this system. Now search for the sectionalizing switch inside the loop with minimum voltage difference across it. Open that switch, it will give the new configuration and note down the power loss.

d) Repeat step (c), till all the tie switches are closed and system is radial. Note down the power loss of final configuration.

e) Final configuration power loss comes out to be (181.2) $\mathrm{kW}$. Calculate percentage power loss reduction using equation (4).

Final radial configuration of 110-Bus using method 3 is explained in Figure 6.

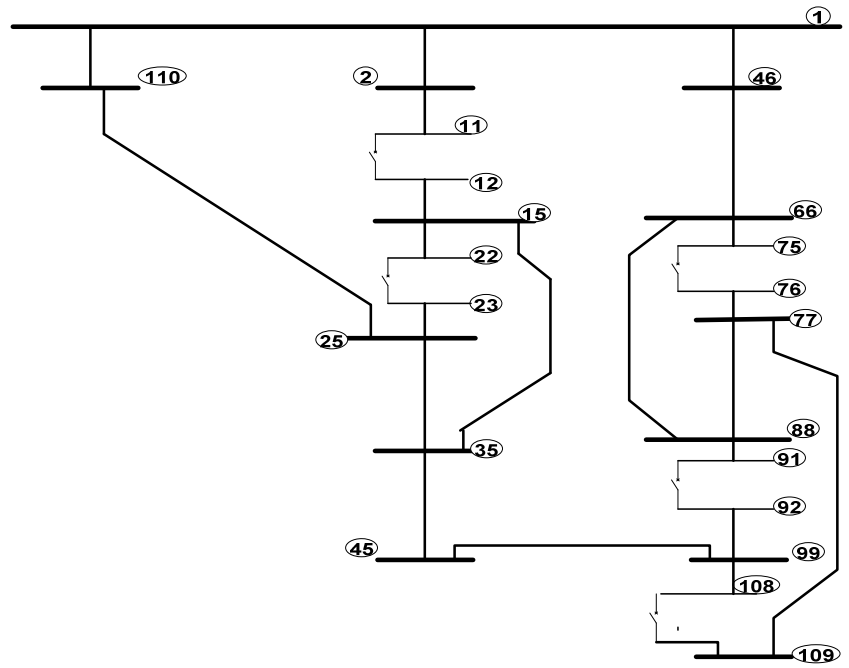

Figure 6. 110-Bus Final radial configuration using method 3

\section{SIMULATION RESULTS AND DISCUSSION}

The proposed method has been tested on 110-Bus radial distribution system to ascertain its effectiveness. For that system, all tie and sectionalizing switches which belong to any loop are considered as candidate switches for reconfiguration problem. The 110 -Bus, $11 \mathrm{kV}$ system consists of three main feeders and five tie lines. There are five tie lines before network reconfiguration because of voltage reduction, long length and overloaded lines in the existing system. For 110-Bus system, the radial real power loss and reactive power loss is $243.6 \mathrm{~kW}$ and $431.9 \mathrm{kVAR}$. And the minimum operating voltage is $9.9 \mathrm{kV}$ in the existing system. Exhaustive technique is used to find the optimal switching configuration and loss minimization to reconfigure this network. There are three methods to get acceptable minimum loss configuration. ETAP is applied for load flow solutions of three methods to manage the optimal switching scheme with minimum loss. Comparison of percent bus voltage improvement at distribution feeders for before and after reconfiguration of the test system are depicted in Table 1 and Figure 7.

Table 1. Percent Voltage Increment of 110-Bus Radial Distribution System

\begin{tabular}{ccccc}
\hline & Base & Method 1 & Method 2 & Method 3 \\
\hline $\begin{array}{c}\text { Total Percentage in Voltage } \\
\text { Increment }\end{array}$ & - & $210.191 \%$ & 206.768 & 195.273 \\
\hline
\end{tabular}




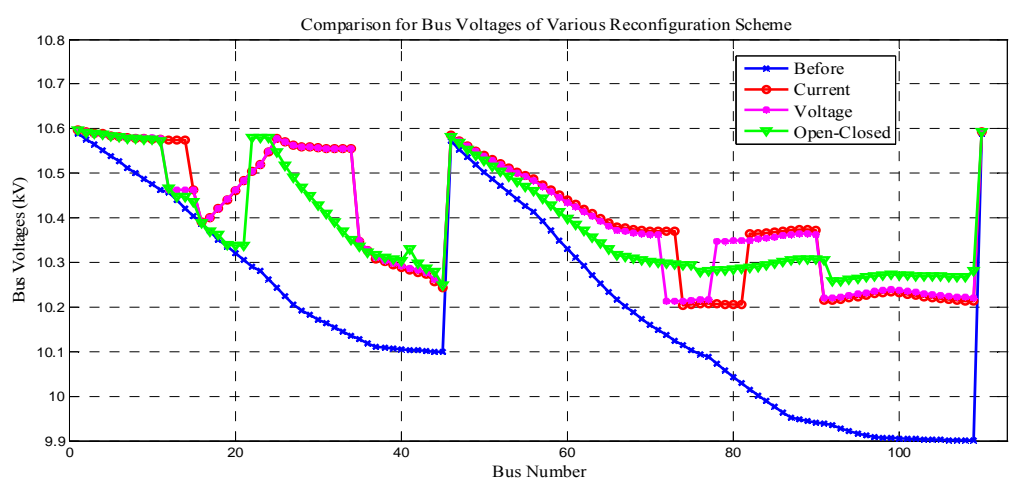

Figure 7. Comparison of operating bus voltages for before and after reconfiguration

From Table 1, minimum branch current method is the best in network reconfiguration process. In Figure 7, before reconfiguration condition is expressed in blue colour and some operating bus voltages are less than $10 \mathrm{kV}$. Red, pink and green colours are indicated for three methods in exhaustive search technique in reconfiguration process. In this condition, all operating bus voltages are dramatically increased above 10.2 $\mathrm{kV}$. In this condition, real power loss and reactive power loss is reduced to $175.3 \mathrm{~kW}$ and $374.1 \mathrm{kVAR}$. Though the aim is reducing the real power loss, the reactive power loss is also reducing due to enhancement in voltage profile.

Comparison of real power loss and reactive power loss curves for three methods in exhaustive algorithm before and after reconfiguration is explained Figure 8 and Figure 9. In the two figures, red, pink and green lines are after reconfiguration conditions for method 1, method 2 and method 3.

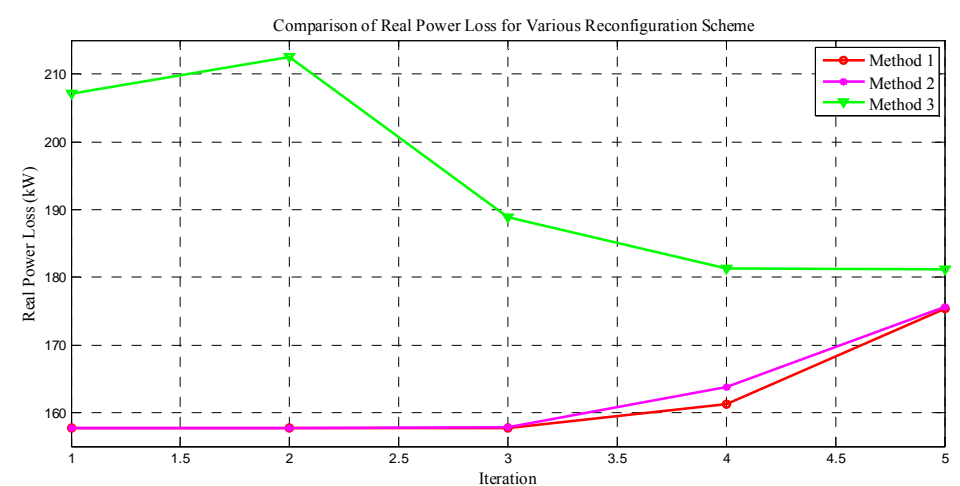

Figure 8. Comparison of real power loss curves for three methods

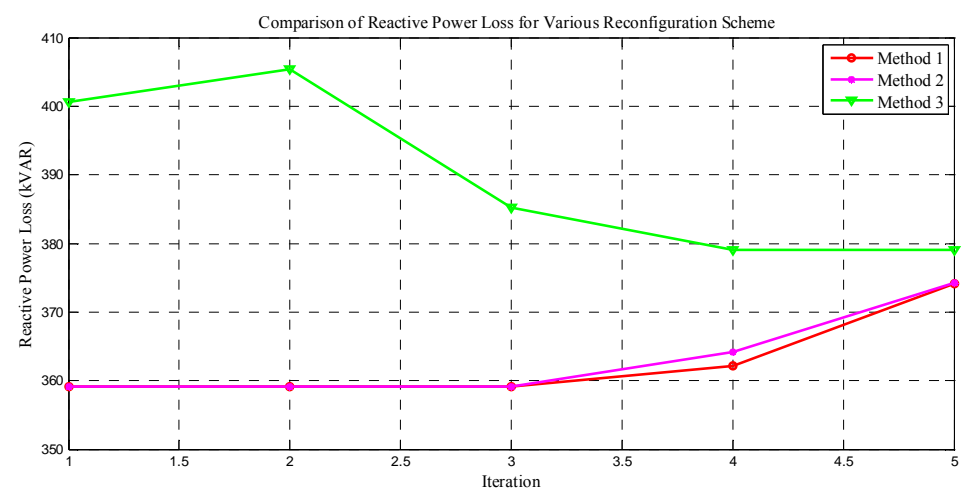

Figure 9. Comparison of reactive power loss curves for three methods 
The percentage reduction in the real power loss and reactive power loss is equal to $28.04 \%$ and $13.4 \%$ for minimum branch current method and the power loss in the rest methods is also reducing. It can be clearly seen that minimum branch current method is more efficient than any other two methods. So, percentage in power loss reduction for three methods that is compared to base case of 110-Bus radial distribution system is depicted in Table 2. The line and load data for 110-Bus radial distribution system is shown in Appendix A.

Table 2. Power Loss Reduction of 110-Bus Radial Distribution System

\begin{tabular}{cccccc}
\hline Case & $\begin{array}{c}\text { Real Power Loss } \\
(\mathrm{kW})\end{array}$ & $\begin{array}{c}\text { Reactive Power } \\
\text { Loss (kVAR) }\end{array}$ & $\begin{array}{c}\text { Real Power Loss } \\
\text { Reduction }(\%)\end{array}$ & $\begin{array}{c}\text { Reactive Power Loss } \\
\text { Reduction (\%) }\end{array}$ & Switches Opened \\
\hline Base & 243.6 & 431.9 & - & - & - \\
Method 1 & 175.3 & 374.1 & 28.04 & 13.4 & $\begin{array}{c}90-91,81-82,73-74, \\
34-35,14-15\end{array}$ \\
Method 2 & 175.6 & 374.3 & 27.92 & 13.3 & $\begin{array}{c}71-72,90-91,77-78, \\
11-12,34-35 \\
\text { Method 3 }\end{array}$ \\
\hline
\end{tabular}

\section{CONCLUSION}

In this paper, the reconfiguration of distribution network under $10 \mathrm{MVA}, 33 / 11 \mathrm{kV}$ transformer is presented. It has three radial outgoing feeders. The base voltage is $11 \mathrm{kV}$ and 110 buses are studied in detail for reconfiguration. Network reconfiguration method improves the voltage profile and reduces losses in the power distribution system simultaneously. Considerable loss reduction is achieved by network reconfiguration method in distribution networks. Exhaustive technique is applied for the network reconfiguration by using ETAP software. According to simulation results, network reconfiguration is the most effective way for the proposed system. The best results are obtained by using minimum current based method among three methods in exhaustive technique as it achieves an optimal loss configuration according to the results of above tables and figures. From these results, total real and reactive power loss reduced from $243.6 \mathrm{~kW}$ and $431.9 \mathrm{kVAR}$ before network reconfiguration state to $175.3 \mathrm{~kW}$ and $374.1 \mathrm{kVAR}$ after network reconfiguration state. Thus, distribution system losses are reduced about $28.04 \%$ and $13.4 \%$.

Appendix A Power Loss Reduction of 110-Bus Radial Distribution System

\begin{tabular}{|c|c|c|c|c|c|c|c|c|c|c|c|}
\hline \multirow{2}{*}{$\begin{array}{c}\text { From } \\
\text { Bus }\end{array}$} & \multirow{2}{*}{$\begin{array}{c}\text { To } \\
\text { Bus }\end{array}$} & \multirow{2}{*}{$\begin{array}{c}\mathrm{R} \\
(\Omega)\end{array}$} & \multirow{2}{*}{$\begin{array}{c}\mathrm{X} \\
(\Omega)\end{array}$} & \multicolumn{2}{|c|}{ Load at Receiving } & \multirow{2}{*}{$\begin{array}{c}\text { From } \\
\text { Bus }\end{array}$} & \multirow{2}{*}{$\begin{array}{c}\text { To } \\
\text { Bus }\end{array}$} & \multirow{2}{*}{$\begin{array}{c}\mathrm{R} \\
(\Omega)\end{array}$} & \multirow{2}{*}{$\begin{array}{c}X \\
(\Omega)\end{array}$} & \multicolumn{2}{|c|}{ Load at Receiving } \\
\hline & & & & P,MW & Q,MVAR & & & & & $\mathrm{P}, \mathrm{MW}$ & Q,MVAR \\
\hline 1 & 2 & 0.0578 & 0.0438 & 0.000 & 0.000 & 62 & 63 & 0.0868 & 0.0658 & 0.011 & 0.007 \\
\hline 2 & 3 & 0.0578 & 0.0438 & 0.086 & 0.058 & 63 & 64 & 0.0868 & 0.0658 & 0.010 & 0.007 \\
\hline 3 & 4 & 0.0578 & 0.0438 & 0.000 & 0.000 & 64 & 65 & 0.0868 & 0.0658 & 0.010 & 0.007 \\
\hline 4 & 5 & 0.0578 & 0.0438 & 0.003 & 0.002 & 65 & 66 & 0.0868 & 0.0658 & 0.044 & 0.029 \\
\hline 5 & 6 & 0.0578 & 0.0438 & 0.061 & 0.041 & 66 & 67 & 0.0721 & 0.0546 & 0.089 & 0.060 \\
\hline 6 & 7 & 0.0721 & 0.0546 & 0.073 & 0.049 & 67 & 68 & 0.0721 & 0.0546 & 0.022 & 0.015 \\
\hline 7 & 8 & 0.0721 & 0.0546 & 0.150 & 0.100 & 68 & 69 & 0.0721 & 0.0546 & 0.005 & 0.004 \\
\hline 8 & 9 & 0.0721 & 0.0546 & 0.015 & 0.010 & 69 & 70 & 0.0721 & 0.0546 & 0.044 & 0.029 \\
\hline 9 & 10 & 0.0721 & 0.0546 & 0.010 & 0.007 & 70 & 71 & 0.0721 & 0.0546 & 0.183 & 0.123 \\
\hline 10 & 11 & 0.0721 & 0.0546 & 0.013 & 0.009 & 71 & 72 & 0.0721 & 0.0546 & 0.006 & 0.004 \\
\hline 11 & 12 & 0.0360 & 0.0273 & 0.016 & 0.011 & 72 & 73 & 0.0721 & 0.0546 & 0.005 & 0.004 \\
\hline 12 & 13 & 0.1086 & 0.0823 & 0.010 & 0.007 & 73 & 74 & 0.0721 & 0.0546 & 0.012 & 0.008 \\
\hline 13 & 14 & 0.1086 & 0.0823 & 0.011 & 0.007 & 74 & 75 & 0.0721 & 0.0546 & 0.118 & 0.080 \\
\hline 14 & 15 & 0.1086 & 0.0823 & 0.010 & 0.007 & 75 & 76 & 0.0721 & 0.0546 & 0.005 & 0.004 \\
\hline 15 & 16 & 0.1086 & 0.0823 & 0.010 & 0.007 & 76 & 77 & 0.0431 & 0.0327 & 0.040 & 0.027 \\
\hline 16 & 17 & 0.1086 & 0.0823 & 0.006 & 0.004 & 77 & 78 & 0.1157 & 0.0877 & 0.012 & 0.008 \\
\hline 17 & 18 & 0.1086 & 0.0823 & 0.010 & 0.007 & 78 & 79 & 0.1157 & 0.0877 & 0.006 & 0.004 \\
\hline 18 & 19 & 0.1086 & 0.0823 & 0.097 & 0.065 & 79 & 80 & 0.1157 & 0.0877 & 0.007 & 0.005 \\
\hline 19 & 20 & 0.1086 & 0.0823 & 0.021 & 0.014 & 80 & 81 & 0.1157 & 0.0877 & 0.007 & 0.005 \\
\hline 20 & 21 & 0.1086 & 0.0823 & 0.016 & 0.011 & 81 & 82 & 0.1157 & 0.0877 & 0.032 & 0.022 \\
\hline 21 & 22 & 0.1086 & 0.0823 & 0.025 & 0.017 & 82 & 83 & 0.1157 & 0.0877 & 0.068 & 0.046 \\
\hline 22 & 23 & 0.0721 & 0.0546 & 0.010 & 0.007 & 83 & 84 & 0.1157 & 0.0877 & 0.005 & 0.004 \\
\hline 23 & 24 & 0.1446 & 0.1096 & 0.010 & 0.007 & 84 & 85 & 0.1157 & 0.0877 & 0.028 & 0.019 \\
\hline 24 & 25 & 0.1446 & 0.1096 & 0.010 & 0.007 & 85 & 86 & 0.1157 & 0.0877 & 0.008 & 0.005 \\
\hline 25 & 26 & 0.1446 & 0.1096 & 0.010 & 0.007 & 86 & 87 & 0.0877 & 0.0877 & 0.006 & 0.004 \\
\hline 26 & 27 & 0.1446 & 0.1096 & 0.010 & 0.007 & 87 & 88 & 0.0431 & 0.0327 & 0.123 & 0.083 \\
\hline 27 & 28 & 0.1446 & 0.1096 & 0.210 & 0.141 & 88 & 89 & 0.0431 & 0.0327 & 0.029 & 0.020 \\
\hline 28 & 29 & 0.1157 & 0.0877 & 0.078 & 0.052 & 89 & 90 & 0.0431 & 0.0327 & 0.005 & 0.004 \\
\hline 29 & 30 & 0.1157 & 0.0877 & 0.006 & 0.004 & 90 & 91 & 0.0431 & 0.0327 & 0.086 & 0.058 \\
\hline 30 & 31 & 0.1157 & 0.0877 & 0.022 & 0.015 & 91 & 92 & 0.0431 & 0.0327 & 0.034 & 0.023 \\
\hline
\end{tabular}

Network Reconfiguration for Loss Reduction and Voltage Profile Improvement of 110-Bus ...(Su Mon Myint) 


\begin{tabular}{|c|c|c|c|c|c|c|c|c|c|c|c|}
\hline 31 & 32 & 0.1157 & 0.0877 & 0.006 & 0.004 & 92 & 93 & 0.1446 & 0.1096 & 0.020 & 0.013 \\
\hline 32 & 33 & 0.1157 & 0.0877 & 0.019 & 0.013 & 93 & 94 & 0.1446 & 0.1096 & 0.122 & 0.082 \\
\hline 33 & 34 & 0.1157 & 0.0877 & 0.006 & 0.004 & 94 & 95 & 0.1086 & 0.0823 & 0.006 & 0.004 \\
\hline 34 & 35 & 0.1157 & 0.0877 & 0.016 & 0.011 & 95 & 96 & 0.1086 & 0.0823 & 0.026 & 0.018 \\
\hline 35 & 36 & 0.1157 & 0.0877 & 0.015 & 0.010 & 96 & 97 & 0.1086 & 0.0823 & 0.006 & 0.004 \\
\hline 36 & 37 & 0.1157 & 0.0877 & 0.015 & 0.010 & 97 & 98 & 0.0431 & 0.0327 & 0.005 & 0.004 \\
\hline 37 & 38 & 0.0431 & 0.0327 & 0.008 & 0.006 & 98 & 99 & 0.0431 & 0.0327 & 0.031 & 0.021 \\
\hline 38 & 39 & 0.0431 & 0.0327 & 0.224 & 0.150 & 99 & 100 & 0.0431 & 0.0327 & 0.064 & 0.043 \\
\hline 39 & 40 & 0.0939 & 0.0711 & 0.008 & 0.005 & 100 & 101 & 0.0431 & 0.0327 & 0.005 & 0.004 \\
\hline 40 & 41 & 0.0431 & 0.0327 & 0.005 & 0.004 & 101 & 102 & 0.0431 & 0.0327 & 0.007 & 0.005 \\
\hline 41 & 42 & 0.0431 & 0.0327 & 0.022 & 0.015 & 102 & 103 & 0.0578 & 0.0438 & 0.015 & 0.010 \\
\hline 42 & 43 & 0.0360 & 0.0273 & 0.053 & 0.036 & 103 & 104 & 0.0431 & 0.0327 & 0.005 & 0.004 \\
\hline 43 & 44 & 0.1346 & 0.1020 & 0.012 & 0.008 & 104 & 105 & 0.0431 & 0.0327 & 0.006 & 0.004 \\
\hline 44 & 45 & 0.1346 & 0.1020 & 0.117 & 0.078 & 105 & 106 & 0.0431 & 0.0327 & 0.012 & 0.008 \\
\hline 1 & 46 & 0.0578 & 0.0438 & 0.005 & 0.004 & 106 & 107 & 0.0431 & 0.0327 & 0.005 & 0.004 \\
\hline 46 & 47 & 0.0578 & 0.0438 & 0.007 & 0.005 & 107 & 108 & 0.0474 & 0.0359 & 0.051 & 0.034 \\
\hline 47 & 48 & 0.0578 & 0.0438 & 0.002 & 0.002 & 108 & 109 & 0.0474 & 0.0359 & 0.008 & 0.006 \\
\hline 48 & 49 & 0.0578 & 0.0438 & 0.037 & 0.025 & 1 & 110 & 0.0133 & 0.010 & 0.011 & 0.007 \\
\hline 49 & 50 & 0.0578 & 0.0438 & 0.173 & 0.116 & & & & & & \\
\hline 50 & 51 & 0.0578 & 0.0438 & 0.045 & 0.030 & & & & & & \\
\hline 51 & 52 & 0.0578 & 0.0438 & 0.010 & 0.007 & & & & & & \\
\hline 52 & 53 & 0.0578 & 0.0438 & 0.056 & 0.038 & & & & & & \\
\hline 53 & 54 & 0.0578 & 0.0438 & 0.013 & 0.008 & & & & & & \\
\hline 54 & 55 & 0.0578 & 0.0438 & 0.043 & 0.029 & & & & & & \\
\hline 55 & 56 & 0.0578 & 0.0438 & 0.013 & 0.009 & & & & & & \\
\hline 56 & 57 & 0.0868 & 0.0658 & 0.038 & 0.025 & & & & & & \\
\hline 57 & 58 & 0.0868 & 0.0658 & 0.015 & 0.010 & & & & & & \\
\hline 58 & 59 & 0.0868 & 0.0658 & 0.011 & 0.007 & & & & & & \\
\hline 59 & 60 & 0.0868 & 0.0658 & 0.084 & 0.056 & & & & & & \\
\hline 60 & 61 & 0.0868 & 0.0658 & 0.019 & 0.013 & & & & & & \\
\hline 61 & 62 & 0.0868 & 0.0658 & 0.010 & 0.007 & & & & & & \\
\hline
\end{tabular}

\section{ACKNOWLEDGEMENTS}

The author wishes to express her special thanks to her parents for their supports. The author is deeply grateful to supervisor, Dr. Soe Win Naing, Associate Professor and Dr. Yan Aung Oo, Professor and Head of Department of Electrical Power Engineering at Mandalay Technological University.

\section{REFERENCES}

[1] Willis, H.L., Marcel Dekker, New York, "Power Distribution Planning Reference Book", 1997.

[2] Benedict, E.; Collins, T.; Gotham, D.; Hoffman, S.; Karipides, D.; Pekarek, S.; and Ramabhadran, R.; "Losses in Electric Power Systems," (1992).

[3] M.E. Baran, Felix F. Wu, "Network Reconfiguration in Distribution System for Loss Reduction and Load Balancing." IEEE Transactions on Power Delivery, 4:2, 1989.

[4] Power Flow Study, http://en.wikipedia.org/wiki/Power-flow- study\# Load-flow

[5] C.M.P dos Sanyos, Latin America, Venezuela "Determination of Electrical Power Losses in Distribution System" IEEE PES Transmission and Distribution Conference and Exposition, pp. 1-5, 2006.

[6] Dagon Seikkan Substation, 2014. A Department Report. Dagon Seikkan Township, Yangon.

[7] Electrical Transient AnalyzerProgran (ETAP), www.etap.com

[8] Grainger, J.; Stevenson, W., McGraw-Hill, New York, "Power System Analysis", 1994.

[9] R. Srinivasa and S. Narasimham, "A New Algorithm for the Network Reconfiguration of Distribution Feeders for Loss Minimization”, IEEE Transaction on Power Delivery, Vol. 7, No. 3, pp. 1484-1491, 1992.

[10] Utkarsh Singh, "Radial Distribution System Reconfiguration for Loss Minimization using Exhaustive Search Techniques”, India, July 2014. 